\title{
Practical guidance for using rivaroxaban in patients with atrial fibrillation: balancing benefit and risk
}

This article was published in the following Dove Press journal:

Vascular Health and Risk Management

10 March 2014

Number of times this article has been viewed

\author{
Sylvia Haas' \\ Christoph Bode ${ }^{2}$ \\ Bo Norrving ${ }^{3}$ \\ Alexander GG Turpie ${ }^{4}$ \\ 'Technical University Munich, Munich, \\ Germany; ${ }^{2}$ Department of Cardiology \\ and Angiology, University of Freiburg, \\ Freiburg, Germany; ${ }^{3}$ Department \\ of Clinical Neuroscience, Lund \\ University Hospital, Lund, Sweden; \\ ${ }^{4}$ Department of Medicine, McMaster \\ University, Hamilton, Ontario, Canada
}

Correspondence: Sylvia Haas Technical University Munich, Normannenstr, 34a, 81 925 Munich, Germany

Tel +4989 91 7191

Fax +4989917177

Email sylvia.haas@Irz.tum.de

\begin{abstract}
Rivaroxaban is a direct factor Xa inhibitor that is widely available to reduce the risk of stroke or systemic embolism in patients with nonvalvular atrial fibrillation and one or more risk factors for stroke. Rivaroxaban provides practical advantages compared with warfarin and other vitamin $\mathrm{K}$ antagonists, including a rapid onset of action, few drug interactions, no dietary interactions, a predictable anticoagulant effect, and no requirement for routine coagulation monitoring. However, questions have emerged relating to the responsible use of rivaroxaban in day-to-day clinical practice, including patient selection, dosing, treatment of patients with renal impairment, conversion from use of vitamin $\mathrm{K}$ antagonists to rivaroxaban and vice versa, coagulation tests, and management of patients requiring invasive procedures or experiencing bleeding or an ischemic event. This article provides practical recommendations relating to the use of rivaroxaban in patients with nonvalvular atrial fibrillation, based on clinical trial evidence, relevant guidelines, prescribing information, and the authors' clinical experience.
\end{abstract}

Keywords: novel oral anticoagulants, direct factor Xa inhibitor, peri-interventional management, practical guidance, rivaroxaban, stroke prevention

\section{Introduction}

Rivaroxaban is a novel oral anticoagulant (NOAC) that is approved in many countries worldwide for reducing the risk of stroke or systemic embolism in patients with nonvalvular atrial fibrillation (AF) and one or more risk factors for stroke. Rivaroxaban has also received approval for use in the prevention of venous thromboembolism after elective hip or knee replacement surgery, the treatment of deep vein thrombosis and pulmonary embolism, the prevention of recurrent venous thromboembolism, and most recently (in the European Union), in combination with acetylsalicylic acid (ASA) with or without clopidogrel or ticlopidine, for the prevention of atherothrombotic events in patients with acute coronary syndrome (ACS) who have elevated cardiac biomarkers. ${ }^{1,2}$

As with the other NOACs, such as dabigatran etexilate and apixaban, and unlike the vitamin $\mathrm{K}$ antagonists (VKAs), including warfarin, rivaroxaban has a rapid onset of action, predictable pharmacokinetics and pharmacodynamics (Table 1), no dietary interactions, and few drug interactions, and has no need for routine coagulation monitoring. ${ }^{3}$ The use of rivaroxaban, as well as of dabigatran and apixaban, was recommended over the use of VKAs in the 2012 updated guidelines for stroke prevention in AF, from the European Society of Cardiology (ESC). ${ }^{4}$ 
Table I Pharmacological properties of rivaroxaban, apixaban, and dabigatran etexilate

\begin{tabular}{|c|c|c|c|}
\hline & Rivaroxaban & Apixaban & $\begin{array}{l}\text { Dabigatran } \\
\text { etexilate }\end{array}$ \\
\hline Target enzyme & Factor $\mathrm{Xa}$ & Factor $\mathrm{Xa}$ & Thrombin \\
\hline Prodrug & No & No & Yes \\
\hline Oral bioavailability (\%) & $80-100$ & $\sim 50$ & $6-7$ \\
\hline $\mathrm{T}_{\max }, \operatorname{median}(\mathrm{h})$ & $2-4$ & $3-4$ & $0.5-2.0$ \\
\hline$T_{1 / 2}(h)$ & $5-13$ & $8-15$ & $12-14$ \\
\hline \multirow[t]{2}{*}{ Route of elimination } & Renal: $66 \%$ ( $36 \%$ as unchanged drug) & Renal: $\sim 27 \%$ & Renal: $80 \%$ \\
\hline & Hepatobiliary: $28 \%^{25}$ & Hepatobiliary: $\sim 75 \%$ & Hepatobiliary: $20 \%$ \\
\hline Metabolism & $\begin{array}{l}\text { CYP3A4, CYP2J2, and CYP-independent } \\
\text { mechanisms; substrate for transporter P-gP }\end{array}$ & $\begin{array}{l}\text { CYP3A4 mainly; substrate } \\
\text { for transporter P-gP }\end{array}$ & $\begin{array}{l}\text { Substrate for } \\
\text { transporter P-gp }\end{array}$ \\
\hline
\end{tabular}

Note: Data from Bayer Pharma AG, Boehringer Ingelheim International GmbH, Bristol-Myers Squibb/Pfizer EEIG. 1,53,54

Abbreviations: CYP, cytochrome P450; P-gP, P-glycoprotein; $T_{1 / 2}$, half-life.

The efficacy and safety of rivaroxaban in patients with nonvalvular AF was assessed in a randomized double-blind Phase III trial (ROCKET AF). The patients enrolled in the ROCKET AF trial had a high risk for stroke, with an average $\mathrm{CHADS}_{2}$ score $^{5}$ of 3.5 ; this high risk was in contrast to the lower risk of the patients enrolled in the RE-LY and ARISTOTLE studies (of dabigatran and apixaban, respectively). ${ }^{6-8}$ The ROCKET AF study established that rivaroxaban $20 \mathrm{mg}$ once daily (od) (15 mg od in patients with a creatinine clearance [CrCl] of $30-49 \mathrm{~mL} / \mathrm{min}$ ) was noninferior to warfarin in reducing the risk of the primary endpoint events (composite of stroke or systemic embolism) in the intention-to-treat population (Table 2). Furthermore, a prespecified analysis of the safety-on-treatment population established that rivaroxaban was superior to warfarin for reducing the risk of stroke or systemic embolism while the patients remained

Table 2 Summary of key findings from the Phase III ROCKET AF trial of rivaroxaban versus warfarin in patients with nonvalvular atrial fibrillation

\begin{tabular}{|c|c|c|c|c|}
\hline & \multicolumn{2}{|c|}{$\begin{array}{l}\text { Event rate (numberl } \\
\text { I } 00 \text { patient-years) }\end{array}$} & \multirow[t]{2}{*}{ Hazard ratio $(95 \% \mathrm{Cl})$} & \multirow[t]{2}{*}{$P$-value } \\
\hline & Rivaroxaban & Warfarin & & \\
\hline $\begin{array}{l}\text { Stroke or systemic embolism } \\
\text { (per-protocol population) }^{\mathrm{a}}\end{array}$ & 1.7 & 2.2 & $0.79(0.66-0.96)$ & $P<0.00$ I (noninferiority) \\
\hline $\begin{array}{l}\text { Stroke or systemic embolism } \\
\text { (on-treatment, safety population) }^{\mathrm{b}}\end{array}$ & 1.7 & 2.2 & $0.79(0.65-0.95)$ & $P=0.02$ (superiority) \\
\hline Ischemic stroke & 1.34 & 1.42 & $0.94(0.75-1.17)$ & $P=0.58 \mathrm{I}$ (superiority) \\
\hline Hemorrhagic stroke & 0.26 & 0.44 & $0.59(0.37-0.93)$ & $P=0.024$ (superiority) \\
\hline $\begin{array}{l}\text { Stroke or systemic embolism } \\
{\text { (ITT population })^{c}}^{c}\end{array}$ & 2.1 & 2.4 & $0.88(0.74-1.03)$ & $\begin{array}{l}P<0.00 I \text { (noninferiority) } \\
P=0.12 \text { (superiority) }\end{array}$ \\
\hline During treatment & 1.7 & 2.2 & $0.79(0.66-0.96)$ & $P=0.02$ (superiority) \\
\hline $\begin{array}{l}\text { Principal safety end point: major and } \\
\text { nonmajor clinically relevant bleeding events }{ }^{d}\end{array}$ & 14.9 & 14.5 & $1.03(0.96-1.11)$ & $P=0.44$ \\
\hline Major bleeding event ${ }^{d}$ & 3.6 & 3.4 & $1.04(0.90-1.20)$ & $P=0.58$ \\
\hline Critical bleeding & 0.8 & 1.2 & $0.69(0.53-0.91)$ & $P=0.007$ \\
\hline Fatal bleeding & 0.2 & 0.5 & $0.50(0.3 \mathrm{I}-0.79)$ & $P=0.003$ \\
\hline Gastrointestinal bleeding & 3.2 & 2.2 & NR & $P<0.001$ \\
\hline Decrease in hemoglobin $\geq 2 \mathrm{~g} / \mathrm{dL}$ & 2.8 & 2.3 & $1.22(1.03-1.44)$ & $P=0.02$ \\
\hline Intracranial hemorrhage ${ }^{d}$ & 0.5 & 0.7 & $0.67(0.47-0.93)$ & $P=0.02$ \\
\hline Nonmajor clinically relevant bleeding event ${ }^{d}$ & 11.8 & 11.4 & $1.04(0.96-1.13)$ & $P=0.35$ \\
\hline Myocardial infarction ${ }^{\mathrm{b}}$ & 0.9 & I.I & $0.81(0.63-1.06)$ & $P=0.121$ \\
\hline All-cause mortality ${ }^{b}$ & 1.9 & 2.2 & $0.85(0.70-1.02)$ & $P=0.073$ \\
\hline
\end{tabular}

Notes: ancluded all patients who received at least one dose of a study drug, did not have a major protocol violation, and who were followed for events that occurred while receiving a study drug or within 2 days after discontinuation. Numbers of patients per treatment arm: rivaroxaban, $n=6,958 ;$ warfarin, $n=7,004$; bincluded patients who received at least one dose of a study drug and who were followed for events, regardless of adherence to the protocol, while they were receiving the assigned study drug or within 2 days after discontinuation. Numbers of patients per treatment arm: rivaroxaban, $\mathrm{n}=7,06 \mathrm{I}$; warfarin, $\mathrm{n}=7,082$; cincluded all patients who underwent randomization and who were followed for events during treatment or after premature discontinuation. Numbers of patients per treatment arm: rivaroxaban, $n=7,081 ;$ warfarin, $n=7,090$; ${ }^{d}$ numbers of patients per treatment arm for the safety analyses: rivaroxaban, $n=7,111$; warfarin, $n=7,125$. Data from Patel et al. ${ }^{8}$

Abbreviations: $\mathrm{Cl}$, confidence interval; ITT, intention-to-treat; NR, not reported. 
on treatment. Similar rates of major bleeding and nonmajor clinically relevant bleeding events were observed between the two treatment groups. However, patients receiving rivaroxaban had significantly lower rates of intracranial hemorrhage and fatal bleeding events compared with patients receiving warfarin, although the rates of major gastrointestinal bleeding events were significantly higher for patients receiving rivaroxaban. Rivaroxaban was also associated with a nonsignificant reduction in all-cause mortality and with numerically fewer myocardial infarctions during treatment. ${ }^{8}$ The efficacy and safety findings were consistent irrespective of age, renal function (including the $15 \mathrm{mg}$ od dose in those with a $\mathrm{CrCl}$ of $30-49 \mathrm{~mL} / \mathrm{min}$ ), and history of stroke/transient ischemic attack, or myocardial infarction. ${ }^{8-11}$

This paper addresses commonly asked questions relating to the use of rivaroxaban for the prevention of stroke in patients with nonvalvular $\mathrm{AF}$, referring to clinical study data, relevant guidelines, the prescribing information, and the authors' clinical experience. However, the recommendations should not be applied to other thromboembolic disorders unless specifically indicated in the prescribing information. When considering the recommendations provided in this paper, individual patient histories and clinical situations should always take precedence.

\section{Use of rivaroxaban for stroke prevention in atrial fibrillation}

Rivaroxaban is recommended as an option for anticoagulation in patients with nonvalvular AF with one or more risk factors for stroke and without specific contraindications; the recommendations and contraindications are listed in Table 3.

Table 3 Rivaroxaban for stroke prevention in patients with nonvalvular AF - recommendations

\begin{tabular}{|c|c|}
\hline Relevant patient group & Recommendations \\
\hline $\begin{array}{l}\text { Patients in whom rivaroxaban } \\
\text { can be used }\end{array}$ & $\begin{array}{l}\text { - Patients with nonvalvular AF with } \geq I \text { risk factors for stroke, such as: congestive heart failure, hypertension, } \\
\text { age } \geq 75 \text { years, diabetes mellitus, and prior stroke or TIA, and who do not have specific contraindications } \\
\text { - Recommended rivaroxaban dose } \\
\text { - In most patients, rivaroxaban } 20 \mathrm{mg} \text { od is recommended, which includes patients in Asian countries } \\
\text { outside of Japan who have normal renal function } \\
\text { - In Japan, rivaroxaban } 15 \mathrm{mg} \text { od is approved for patients with nonvalvular AF with normal renal function }{ }^{24} \\
\text { - Patients with moderate renal impairment: }(\mathrm{CrCl} 30-49 \mathrm{~mL} / \mathrm{min}): 15 \mathrm{mg} \text { od is generally recommended } \\
\text { (I0 mg od is recommended in Japan })^{\mathrm{a}} \\
\text { - Patients with severe renal impairment: }(\mathrm{CrCl} 15-29 \mathrm{~mL} / \mathrm{min}), 15 \mathrm{mg} \text { od is recommended but should be } \\
\text { used with caution owing to the risk of increased rivaroxaban exposure }\end{array}$ \\
\hline $\begin{array}{l}\text { Patients who should not use } \\
\text { rivaroxaban }\end{array}$ & $\begin{array}{l}\text { Contraindications } \\
\text { - Hypersensitivity to rivaroxaban or excipients } \\
\text { - Clinically significant active bleeding, or lesion or condition at significant risk of major bleeding } \\
\text { - Hepatic disease associated with coagulopathy, including cirrhotic patients with a Child-Pugh grade of B or C } \\
\text { - Concomitant treatment with any other anticoagulant agent } \\
\text { - Pregnancy or breast feeding } \\
\text { Use not recommended } \\
\text { - Renal insufficiency with } \mathrm{CrCl}<\mathrm{I} 5 \mathrm{~mL} / \mathrm{min} \\
\text { - Patients aged }<18 \text { years (no pediatric data are available) } \\
\text { - Prosthetic heart valve(s) } \\
\text { - Concomitant treatment with strong inhibitors of CYP3A4 and P-gP, such as HIV protease inhibitors } \\
\text { (eg, ritonavir) or azole antimycotics (eg, ketoconazole) } \\
\text { - Patients with an increased bleeding risk, such as } \\
\text { - Congenital or acquired bleeding disorders } \\
\text { - Uncontrolled severe arterial hypertension } \\
\text { - Active ulcerative Gl disease } \\
\text { - Vascular retinopathy } \\
\text { - Bronchiectasis or history of pulmonary bleeding } \\
\text { - Rivaroxaban (I5-20 mg od) is not recommended in patients who require dual antiplatelet therapy (eg, ASA } \\
\text { plus a thienopyridine) } \\
\text { - This includes patients with a recent ACS or who have recently received PCI }\end{array}$ \\
\hline
\end{tabular}

Notes: Rivaroxaban should only be prescribed if a positive benefit-risk balance is likely based on the patient's overall clinical presentation. For cases in which caution is recommended, regular assessments (eg, $\mathrm{CrCl}$, bleeding assessments) should be incorporated into the overall management plan. ${ }^{\mathrm{a}} \mathrm{To}$ help determine appropriate dosing, renal function should be assessed in all patients (irrespective of age) before rivaroxaban is initiated, although treatment should not be delayed if renal function cannot be assessed immediately. Data from Bayer Pharma AG.'

Abbreviations: ACS, acute coronary syndrome; AF, atrial fibrillation; ASA, acetylsalicylic acid; CrCl, creatinine clearance; CYP, cytochrome P450; GI, gastrointestinal; HIV, human immunodeficiency virus; NSAID, nonsteroidal anti-inflammatory drug; od, once daily; P-gp, P-glycoprotein; PCI, percutaneous coronary intervention; TIA, transient ischemic attack. 


\section{Once-daily administration of rivaroxaban in atrial fibrillation}

Because of the relatively short half-life of rivaroxaban, questions have been raised about the od dosing used in AF. Different dose regimens of rivaroxaban have been studied in a number of clinical trials across several thromboembolic indications. Data from the Phase I pharmacokinetic and pharmacodynamic studies suggested that od dosing could be effective - a possibility that was subsequently confirmed by Phase II dose-finding studies. ${ }^{3,12,13}$ Some of the pharmacodynamic effects of rivaroxaban (eg, inhibition of factor Xa activity and thrombin generation) were still evident at 24 hours after dosing. ${ }^{14,15}$ The efficacy and safety of od dosing in stroke prevention was subsequently demonstrated in ROCKET AF. To ensure the optimal benefit from od dosing (which has been identified as a significant advantage for long-term anticoagulation), the following recommendations may guide clinicians.

\section{Recommendations}

- To ensure compliance and adherence, patients should receive comprehensive information about their disease and, in particular, about the risk of stroke and other embolic complications of $\mathrm{AF}$

- Patients should also be advised to take rivaroxaban $20 \mathrm{mg}$ (or $15 \mathrm{mg}$ ) od with food at the same time each day

- In case of a missed dose, patients should take rivaroxaban immediately and, on the following day, continue with the od intake as recommended.

\section{Patients with renal impairment}

Of the administered rivaroxaban dose, one-third is excreted via the kidneys as active drug. Therefore, renal impairment increases rivaroxaban exposure, which may increase the risk of bleeding. ${ }^{16}$ Further analyses from the ROCKET AF trial showed consistent efficacy and safety outcomes for rivaroxaban, in patients with and without moderate renal impairment (administered $15 \mathrm{mg}$ and 20 mg od doses, respectively). ${ }^{9}$ The patients with a $\mathrm{CrCl}$ $<30 \mathrm{~mL} / \mathrm{min}$ were excluded from ROCKET AF, ${ }^{8}$ and the use of rivaroxaban $15 \mathrm{mg}$ od in this group (as approved in some countries) is based on extrapolation from pharmacologic data. ${ }^{13,16}$

\section{Recommendations}

- We recommend that renal function should be assessed in all patients, using the Cockcroft-Gault formula to estimate the $\mathrm{CrCl}$, before initiating long-term rivaroxaban therapy and at least once annually thereafter ${ }^{17}$

- For patients with existing renal impairment, we recommend regular assessments of renal function

- Assessment of renal function is recommended in situations when a deterioration in renal function may be expected, including but not restricted to the following

- Acute dehydration

- Surgery

- Infection

- Addition of comedications associated with nephrotoxicity, such as nonsteroidal anti-inflammatory drugs (NSAIDS) (eg, ibuprofen or naproxen), angiotensinconverting enzyme inhibitors, radiographic contrast dyes, aminoglycoside antibiotics (eg, gentamicin or tobramycin), and zoledronate

- Close monitoring of renal function and assessment of the plasma drug level is recommended with rivaroxaban $15 \mathrm{mg}$ od in patients with a $\mathrm{CrCl}$ of $15-29 \mathrm{~mL} / \mathrm{min}$, to ensure that there is no accumulation of the drug

- If the $\mathrm{CrCl}$ declines to $<50 \mathrm{~mL} / \mathrm{min}$, the rivaroxaban dose should be reduced from $20 \mathrm{mg}$ od to $15 \mathrm{mg}$ od

- Rivaroxaban is not recommended in patients with a $\mathrm{CrCl}<15 \mathrm{~mL} / \mathrm{min}$; if the $\mathrm{CrCl}$ falls below $15 \mathrm{~mL} / \mathrm{min}$, rivaroxaban should be discontinued (Figure 1).

\section{Age, sex, body weight and ethnicity}

Age is an independent risk factor for both thromboembolic and bleeding events, ${ }^{18}$ and increasing age is associated with a decline in renal function. ${ }^{19}$ Rivaroxaban clearance is reduced in elderly subjects, mainly owing to decreased renal function. The terminal half-life of rivaroxaban is longer in elderly than in younger individuals (11-13 hours versus 5-9 hours). ${ }^{20,21}$ However, sex has no significant influence on the pharmacokinetics and pharmacodynamics of rivaroxaban..$^{22} \mathrm{~A}$ study of healthy subjects showed that a body weight of $\leq 50 \mathrm{~kg}(\sim 110 \mathrm{lbs})$ had only a small influence on plasma concentrations, ${ }^{23}$ data are not available for patients with very low body weights. Although differences in rivaroxaban exposure were observed between the various ethnic groups investigated, they were within the normal magnitude of interindividual variability. The greatest difference compared with Caucasians was observed for Japanese subjects, with an estimated increase in rivaroxaban exposure - ie, the exposure in the Japanese patients who received a $15 \mathrm{mg}$ od dose would be comparable to that in Caucasian patients who received a $20 \mathrm{mg}$ od dose. ${ }^{24,25}$ This, together with the lower 


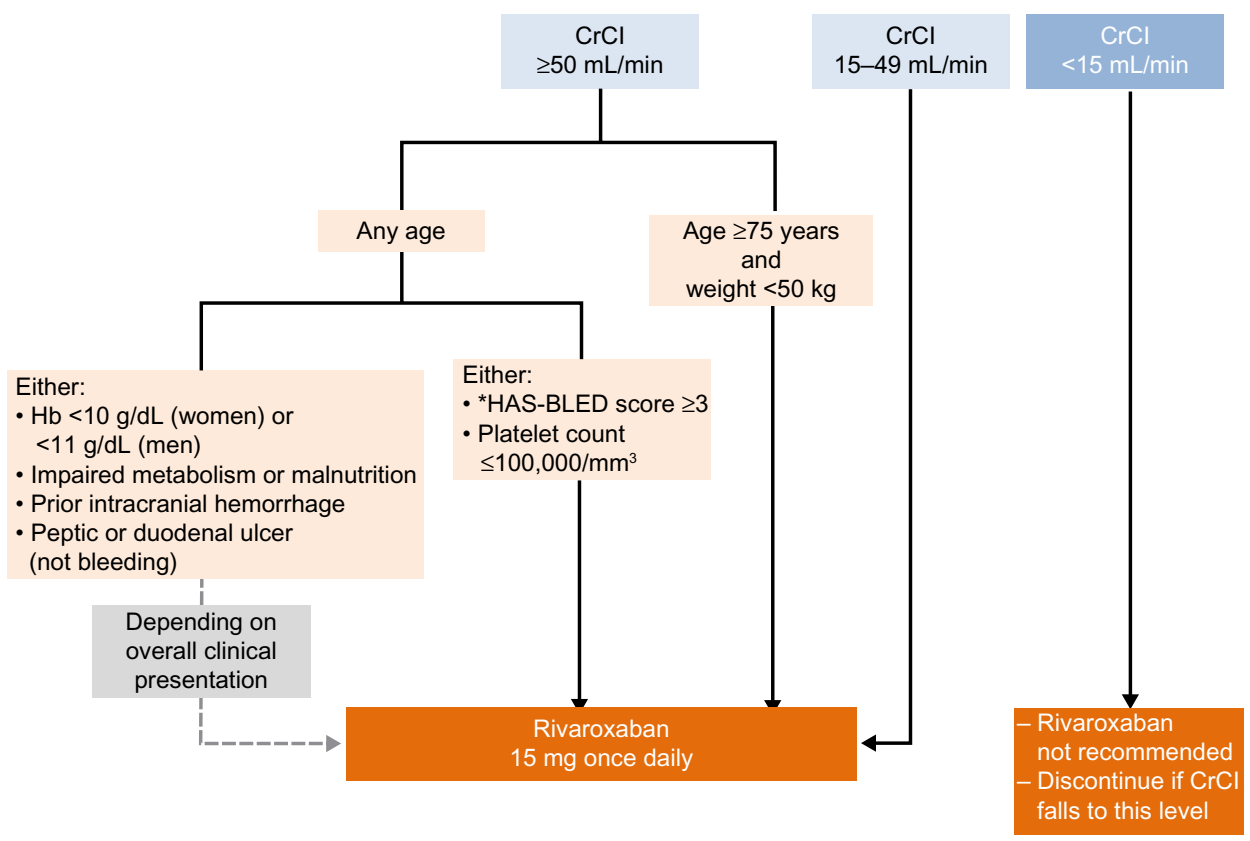

Figure I Algorithm for use of a reduced dose of rivaroxaban ( $15 \mathrm{mg}$ once daily instead of $20 \mathrm{mg}$ once daily) in patients with nonvalvular atrial fibrillation, according to the patient characteristics.

Note: *HAS-BLED bleeding score. Data from Pisters et al. ${ }^{55}$

Abbreviations: $\mathrm{CrCl}$, creatinine clearance; $\mathrm{Hb}$, hemoglobin.

anticoagulation targets used in Japanese clinical practice, formed the dose rationale for the Phase III J-ROCKET AF study investigating rivaroxaban versus warfarin in Japanese patients with AF and the subsequent approval of the $15 \mathrm{mg}$ od dose in Japan for this indication.

\section{Recommendations}

- No dose adjustment is necessary based on age, sex, or weight individually, or on ethnicity (except for Japanese patients $-15 \mathrm{mg}$ od is the approved dose in Japan)

- We recommend that rivaroxaban $15 \mathrm{mg}$ od should be considered for patients with AF who are $>75$ years of age and who have a low body weight $(\leq 50 \mathrm{~kg})$ (Figure 1).

\section{Patients with hepatic impairment}

A Phase I study showed that subjects with mild hepatic impairment (Child-Pugh A) ${ }^{26}$ exhibited only minor changes in rivaroxaban pharmacokinetics, which were almost the same as those of their matched healthy controls. The rivaroxaban exposure was increased in subjects with moderate hepatic impairment, leading to an enhanced pharmacodynamic effect. ${ }^{27}$

\section{Recommendations}

- We recommend that hepatic function should be assessed before starting rivaroxaban therapy in patients who have a history of or active liver disease
- No dose adjustment is needed in patients with mild hepatic impairment (Child-Pugh A); rivaroxaban is contraindicated in patients with hepatic disease associated with coagulopathy and clinically relevant bleeding risk, including cirrhotic patients with Child-Pugh B or C (Table 3).

\section{Clinically relevant drug-drug interactions}

In contrast to VKAs, rivaroxaban has only few clinically relevant interactions with other drugs. However, the coadministration of anticoagulants with agents that also affect the hemostatic system (such as antiplatelet agents and NSAIDs) increases the risk of bleeding. In the ROCKET AF trial, the use of ASA $\leq 100 \mathrm{mg}$ /day was permitted as a comedication: as expected, the use of ASA independently increased the risk of major bleeding events; however, this occurred in both treatment groups. ${ }^{28}$ Additionally, because rivaroxaban is mainly metabolized by cytochrome P450 3A4 and is a substrate of P-glycoprotein, drugs that interfere with these pathways may influence rivaroxaban exposure (Table 4). ${ }^{29}$

\section{Recommendations}

- Caution is needed if rivaroxaban is coadministered with drugs affecting hemostasis, such as NSAIDs, platelet inhibitors, fibrinolytic agents, or other antithrombotic agents. 
Table 4 Potential interactions between rivaroxaban and the drugs affecting the CYP3A4 and P-gP pathways

\begin{tabular}{|c|c|c|c|c|}
\hline & $\begin{array}{l}\text { Strong inhibitors of both } \\
\text { CYP3A4 and P-gP }\end{array}$ & $\begin{array}{l}\text { Moderate to strong } \\
\text { inhibitors of CYP3A4 } \\
\text { or P-gp }\end{array}$ & $\begin{array}{l}\text { Strong CYP3A4 } \\
\text { inducers }\end{array}$ & $\begin{array}{l}\text { Substrates of } \\
\text { CYP3A4 or P-gP }\end{array}$ \\
\hline $\begin{array}{l}\text { Effect on rivaroxaban } \\
\text { plasma concentrations }\end{array}$ & $\begin{array}{l}\text { Increase rivaroxaban plasma } \\
\text { concentrations }\end{array}$ & $\begin{array}{l}\text { Increase rivaroxaban } \\
\text { plasma concentrations but } \\
\text { not clinically relevant }\end{array}$ & $\begin{array}{l}\text { May decrease rivaroxaban } \\
\text { concentrations }\end{array}$ & $\begin{array}{l}\text { No clinically } \\
\text { relevant effect }\end{array}$ \\
\hline Drugs & $\begin{array}{l}\text { HIV protease inhibitors (eg, } \\
\text { ritonavir); azole antimycotics } \\
\text { (eg, ketoconazole, itraconazole, } \\
\text { voriconazole, posaconazole); } \\
\text { conivaptan }\end{array}$ & $\begin{array}{l}\text { Fluconazole; erythromycin; } \\
\text { clarithromycin; telithromycin; } \\
\text { amiodarone; verapamil }\end{array}$ & $\begin{array}{l}\text { Rifampicin;' phenytoin; } \\
\text { carbamazepine; } \\
\text { phenobarbital; } \\
\text { St John's wort }{ }^{\text {b }}\end{array}$ & $\begin{array}{l}\text { Digoxin; atorvastatin; } \\
\text { midazolam }\end{array}$ \\
\hline $\begin{array}{l}\text { Recommendation in } \\
\text { patients receiving } \\
\text { rivaroxaban }\end{array}$ & $\begin{array}{l}\text { Do not coadminister with } \\
\text { rivaroxaban }\end{array}$ & $\begin{array}{l}\text { Permitted; use with caution } \\
\text { in patients with renal } \\
\text { impairment or at an } \\
\text { increased bleeding risk }\end{array}$ & Permitted; use with caution & Permitted \\
\hline
\end{tabular}

Notes: aBecause of limited clinical data, coadministration of rivaroxaban with dronedarone should be avoided;' bUS prescribing information stipulates that concomitant use of rivaroxaban with drugs that are combined P-gP and strong CYP3A4 inducers (eg, carbamazepine, phenytoin, rifampicin, St John's wort) should be avoided. ${ }^{2}$ Data from Bayer Pharma AG and Janssen Pharmaceuticals Inc.,

Abbreviations: CYP, cytochrome P450; P-gp, P-glycoprotein

We recommend paracetamol over NSAIDs for pain control

- Coadministration of rivaroxaban (at the approved doses for patients with AF) with ASA alone ( $>100 \mathrm{mg}$ per day) or with ASA plus clopidogrel (or other thienopyridines, such as ticlopidine or prasugrel) or plus other adenosine diphosphate (ADP) P2Y12 receptor antagonists (such as ticagrelor) should be avoided

- In patients with an increased risk of upper gastrointestinal bleeding, we recommend proton pump inhibitor treatment to be considered. ${ }^{30}$

\section{Converting from other anticoagulants to rivaroxaban and vice versa}

When converting patients from one anticoagulant to another, it is important to maintain adequate (and not excessive) anticoagulation throughout the transition period.

\section{Converting from a VKA to rivaroxaban}

In case of such a therapy conversion, the following recommendations should be followed (Figure 2A).

\section{Recommendations}

- When converting patients from a VKA to rivaroxaban, the VKA should be stopped and the international normalized ratio (INR) monitored closely to assess the residual anticoagulant effects of the $\mathrm{VKA}^{31}$

- Rivaroxaban should be started when the INR approaches the lower end of the recommended therapeutic range
(INR 2.0-3.0), which depends on the VKA functional half-life

- After treatment with warfarin or acenocoumarol (elimination half-life of 40-70 hours and 3-10 hours, respectively), ${ }^{32}$ rivaroxaban should be started when the INR is $2.5-2.9^{33}$

- After treatment with phenprocoumon (elimination half-life of 4-6 days), ${ }^{32}$ rivaroxaban should be started when the INR is $\leq 2.5^{33}$

- In patients with a high risk of bleeding, we recommend starting rivaroxaban when the INR is approaching the lower part of the target range, ie, INR 2.0

- It should be noted that elderly patients with very low weekly doses of VKAs may require a longer time to diminish the effects of VKA treatment.

\section{Converting from rivaroxaban to a VKA}

If a transition from rivaroxaban to a VKA is required, the recommendations outlined below should be followed (Figure 2B).

\section{Recommendations}

- When converting from rivaroxaban to a VKA, both drugs should be coadministered, with a preselected starting dose of VKA given for the first 2 days and INR-guided VKA dosing given thereafter. Rivaroxaban can be discontinued once the INR is $\geq 2.0^{33}$

- During the coadministration period, the INR testing should be performed, ideally, 24 hours after the previous rivaroxaban dose $^{31}$ but in those taking rivaroxaban in the evening, at least 12 hours after and before the next rivaroxaban dose. 


\section{A}

- Start rivaroxaban when the INR is 2.5-2.9, when converting from warfarin or acenocoumarol

- Start rivaroxaban when the INR is $\leq 2.5$, when converting from phenprocoumon

- In patients with a higher risk or bleeding, start rivaroxaban once the INR is in the lower half of the target range

(INR 2.0-2.5), when converting from any VKA

\begin{tabular}{|c|c|c|}
\hline VKA & Stop VKA & Rivaroxaban \\
\hline
\end{tabular}

B

- Conduct INR measurement of VKAs before the next rivaroxaban dose (or 24 hours after the last rivaroxaban dose)

- The coadministration period may vary depending on time for VKA therapy to

- Rivaroxaban can be reach the target INR range discontinued once the INR is $\geq 2.0$

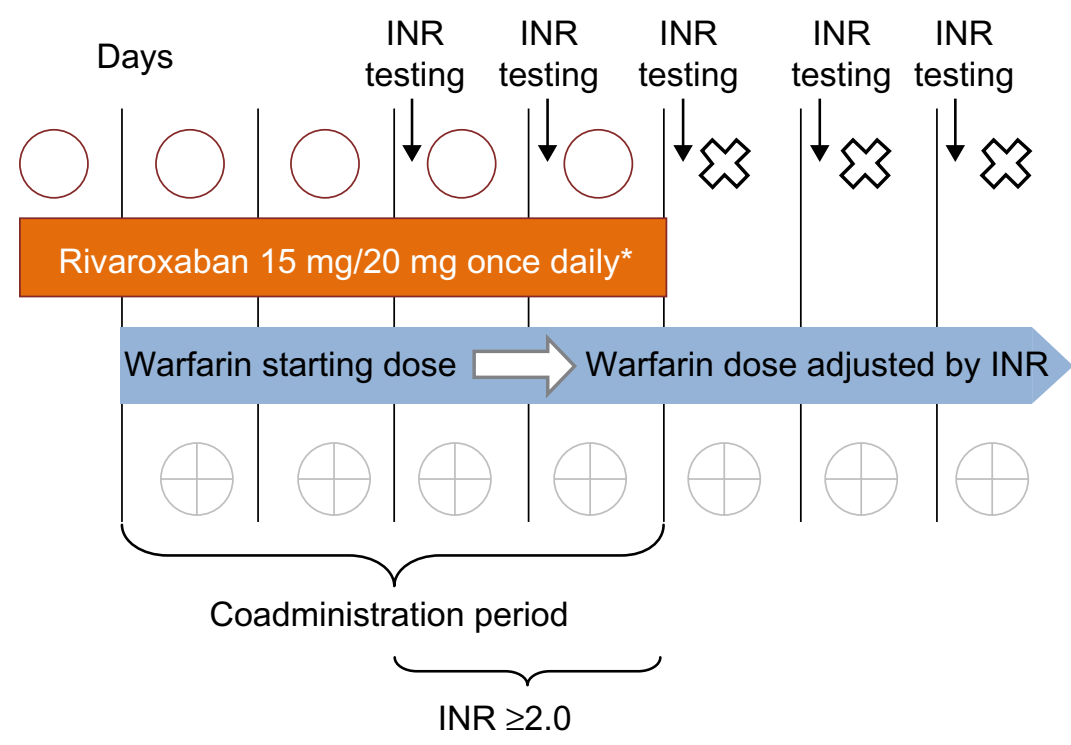

Figure 2 (A) Switching from VKAs to rivaroxaban. (B) Switching from rivaroxaban to VKAs.

Note: * $15 \mathrm{mg}$ od in patients with a $\mathrm{CrCl} 15-49 \mathrm{~mL} / \mathrm{min}$.

Abbreviations: $\mathrm{CrCl}$, creatinine clearance; INR, international normalized ratio; od, once daily; VKA, vitamin $\mathrm{K}$ antagonist.

\section{Switching between rivaroxaban and a parenteral anticoagulant (and vice versa)}

In certain clinical situations, parenteral anticoagulation may be needed, such as in patients who are developing ACS (see the section "Managing acute coronary syndrome in patients with atrial fibrillation receiving rivaroxaban").
Because rivaroxaban has a fast onset of action, switching between rivaroxaban and a parenteral agent is simple.

\section{Recommendations}

- When switching from rivaroxaban to a parenteral anticoagulant, the first dose of the parenteral agent should be given when the next dose of rivaroxaban is due ${ }^{31}$ 
- When switching from a parenteral agent to rivaroxaban, the first dose of rivaroxaban should be given when the next dose of the parenteral anticoagulant (eg, low molecular weight heparin) is due or at the time of discontinuation of an intravenously administered drug (eg, intravenous unfractionated heparin). ${ }^{31}$

\section{Managing patients requiring elective or emergency surgery}

To minimize the risk of bleeding, invasive procedures should be performed when the rivaroxaban plasma concentration is at its lowest. The maximum plasma concentrations are reached 2-4 hours after dosing, and rivaroxaban has a halflife of 5-9 or 11-13 hours in younger or elderly individuals, respectively. ${ }^{20,21}$ Detailed recommendations are given in Figure 3.

\section{Recommendations}

- When the procedure/surgery is elective, rivaroxaban should be stopped at least 24 hours before the procedure or at least 48 hours before procedures carrying an increased bleeding risk (including spinal surgeries and procedures involving the central nervous system)

- When the procedure cannot be delayed (eg, in an emergency), the increased risk of bleeding should be assessed against the urgency of the procedure

- In patients who require emergency surgery and where there were no bleeding events, we do not recommend the prophylactic use of hemostatic blood products, such as prothrombin complex concentrate (PCC), for reversal of the effects of rivaroxaban. However, in cases of severe bleeding, PCC should be considered (see the section "Management of bleeding complications during rivaroxaban therapy")

- After the procedure, rivaroxaban should be restarted at the same dose, once adequate hemostasis has been established (eg, 24 hours after surgery)

- In patients undergoing procedures that carry a low bleeding risk (eg, abscess incision or simple tooth extraction), a consideration should be given to avoiding interruption of rivaroxaban therapy, although performing procedures during the first 12 hours after intake should be avoided whenever possible

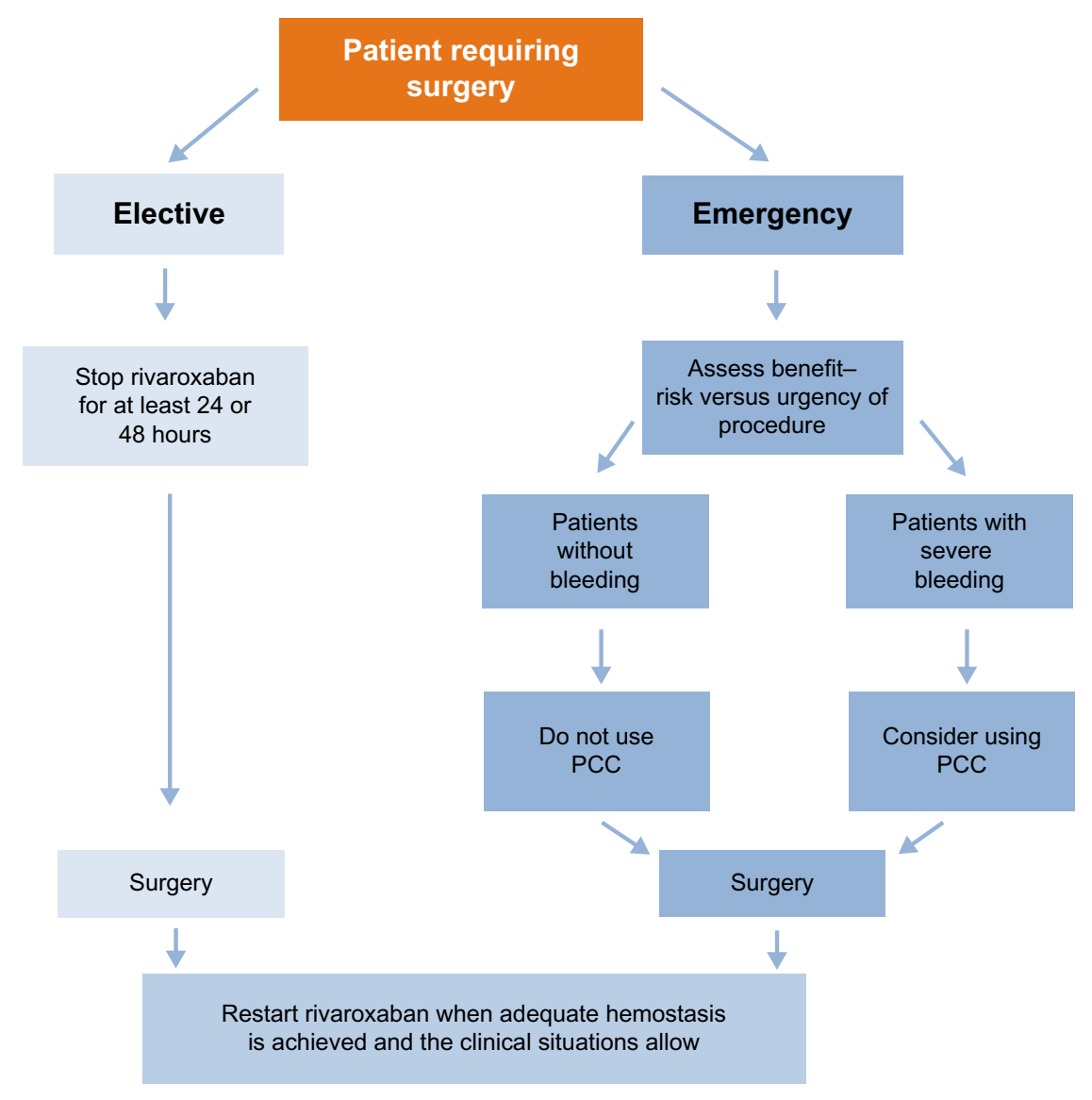

Figure 3 Managing patients requiring an invasive procedure or surgery. Abbreviation: PCC, prothrombin complex concentrate. 
- Because of its short half-life and rapid onset of action, bridging with a parenteral anticoagulant is not required before or after surgery in rivaroxaban-treated patients and therefore should be avoided.

\section{Management of patients with atrial fibrillation experiencing an ischemic event: ischemic stroke}

Thrombolytic agents are recommended as an early therapy after an ischemic stroke unless there are contraindications. $^{34-36}$ The available guidelines state that VKA-treated patients should not undergo thrombolysis until the INR is $\leq 1.7 .{ }^{37}$ After an acute ischemic stroke, endovascular therapy is not recommended in the guidelines because robust data (including those in patients receiving anticoagulation) are lacking. ${ }^{34-36}$ No case series or clinical trial has yet reported the outcomes of the use of thrombolytic agents or endovascular therapy in patients receiving rivaroxaban. The recommendations for the management of patients with atrial fibrillation experiencing ischemic stroke are described in Figure 4.

\section{Recommendations}

- After an ischemic stroke in a patient receiving rivaroxaban, we recommend that thrombolytic agents should not be administered unless there is reliable information that the most recent dose of rivaroxaban was taken at least 24 hours previously or a chromogenic factor Xa assay confirms no residual anticoagulant effect. A normal prothrombin time (PT) value (measured using a rivaroxaban-sensitive reagent) suggests there is no clinically relevant anticoagulant effect of rivaroxaban (see the section "Laboratory testing of rivaroxaban")

- In patients with an ischemic stroke and a large infarct, anticoagulants (including rivaroxaban) should not be restarted before approximately 2 weeks after the stroke and only after confirmation, with neuroimaging, that the risk of hemorrhagic conversion has subsided ${ }^{31}$

- In patients with an ischemic stroke and a small or moderate infarct size, restarting the anticoagulant (including rivaroxaban) therapy after approximately 3 and 6 days, respectively, is recommended. ${ }^{31}$ Before restarting, the blood pressure should be controlled, and the platelet count must be within normal limits ${ }^{38}$

- No delay in restarting the anticoagulant (including rivaroxaban) is required after a transient ischemic attack

- In patients who have experienced a non-central nervous system, systemic embolism, rivaroxaban can be initiated or restarted as soon as the patient is stable following the acute therapy.

\section{Managing acute coronary syndrome in patients with atrial fibrillation receiving rivaroxaban}

After an ACS event, the current guidelines advocate a period of dual antiplatelet therapy, and in patients with concurrent

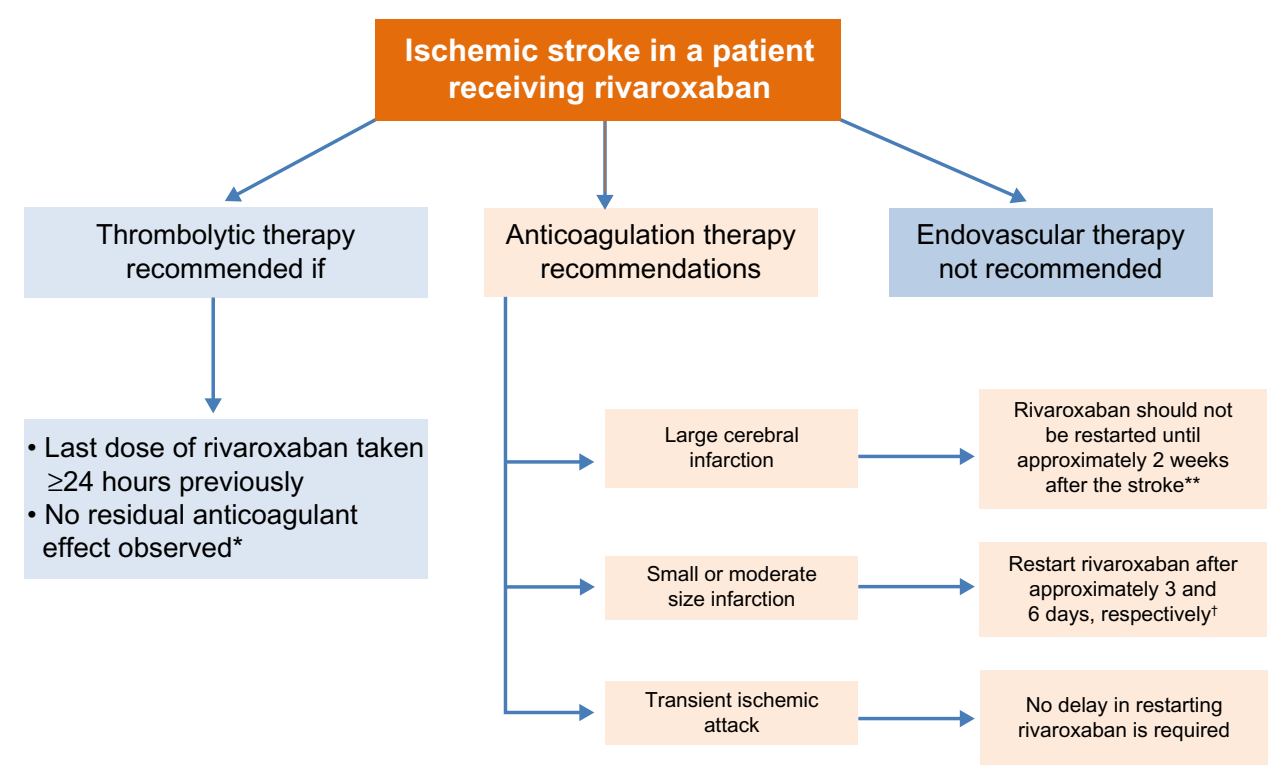

Figure 4 Management of patients with atrial fibrillation experiencing ischemic stroke.

Notes: *Confirmed with a chromogenic anti-factor Xa assay (or PT assay with a rivaroxaban-sensitive reagent, if anti-factor Xa assays are not available); **after confirmation, with neuroimaging, that the risk of hemorrhagic conversion has subsided; tin patients who have controlled blood pressure and a normal platelet count. Abbreviation: PT, prothrombin time. 
AF, oral anticoagulation is also indicated. ${ }^{4,39-41}$ The ATLAS 2 TIMI 51 trial showed significant benefits when very low doses of rivaroxaban (2.5 mg twice daily) were added to the standard antiplatelet therapy (ASA plus a thienopyridine [mostly clopidogrel]) in patients with a recent $\mathrm{ACS} .{ }^{42}$ This regimen has been approved by the European Medicines Agency (EMA), for patients with ACS who have elevated cardiac biomarkers. However, patients with AF who required higher doses of rivaroxaban were excluded from the ATLAS 2 TIMI 51 trial, and the ROCKET AF trial excluded patients receiving chronic dual antiplatelet therapy. ${ }^{8}$ Therefore, at present, there is no evidence to support rivaroxaban use in patients with AF who develop ACS and require dual antiplatelet therapy.

\section{Recommendations}

- For a rivaroxaban-treated patient with AF experiencing ACS or requiring a percutaneous coronary intervention, coronary artery bypass grafting, or dual antiplatelet therapy, we recommend that rivaroxaban be discontinued and that patients are managed with a VKA, in compliance with current guidelines ${ }^{4,39-41}$

- Patients in the catheterization laboratory or in an intensive care unit should also be managed according to the current guidelines and transitioned to an appropriate parenteral anticoagulant as required

- Once dual antiplatelet therapy is no longer required and has been discontinued, it may be appropriate to consider restarting or switching to rivaroxaban
- Rivaroxaban may be administered concomitantly with ASA alone at doses $\leq 100 \mathrm{mg} /$ day, and it remains important to evaluate the risk of bleeding events.

\section{Management of bleeding complications during rivaroxaban therapy}

If bleeding occurs in a patient treated with a NOAC (including rivaroxaban), it is essential to clarify when the last dose was taken, to establish what concentration of drug in the blood should be expected. Additionally, it is also important to assess the patient-related bleeding risk (such as patient inherent bleeding diathesis), comorbidities (such as renal insufficiency), and comedications (in particular, antiplatelet therapy or NSAIDs) (Figure 5). General recommendations for the management of bleeding complications during rivaroxaban therapy are outlined in Figure 6.

\section{Recommendations}

- In cases of severe or life-threatening bleeding, specific procoagulant reversal agents, such as PCC, should be considered, ${ }^{33}$ although the clinical experience with these in rivaroxaban-treated patients is limited ${ }^{31,43,44}$

- We recommend the use of PCC over activated PCC (factor eight inhibitor bypass activity [FEIBA]) and recombinant factor VIIa because their prothrombotic potential may be higher than that of $\mathrm{PCC}^{33}$

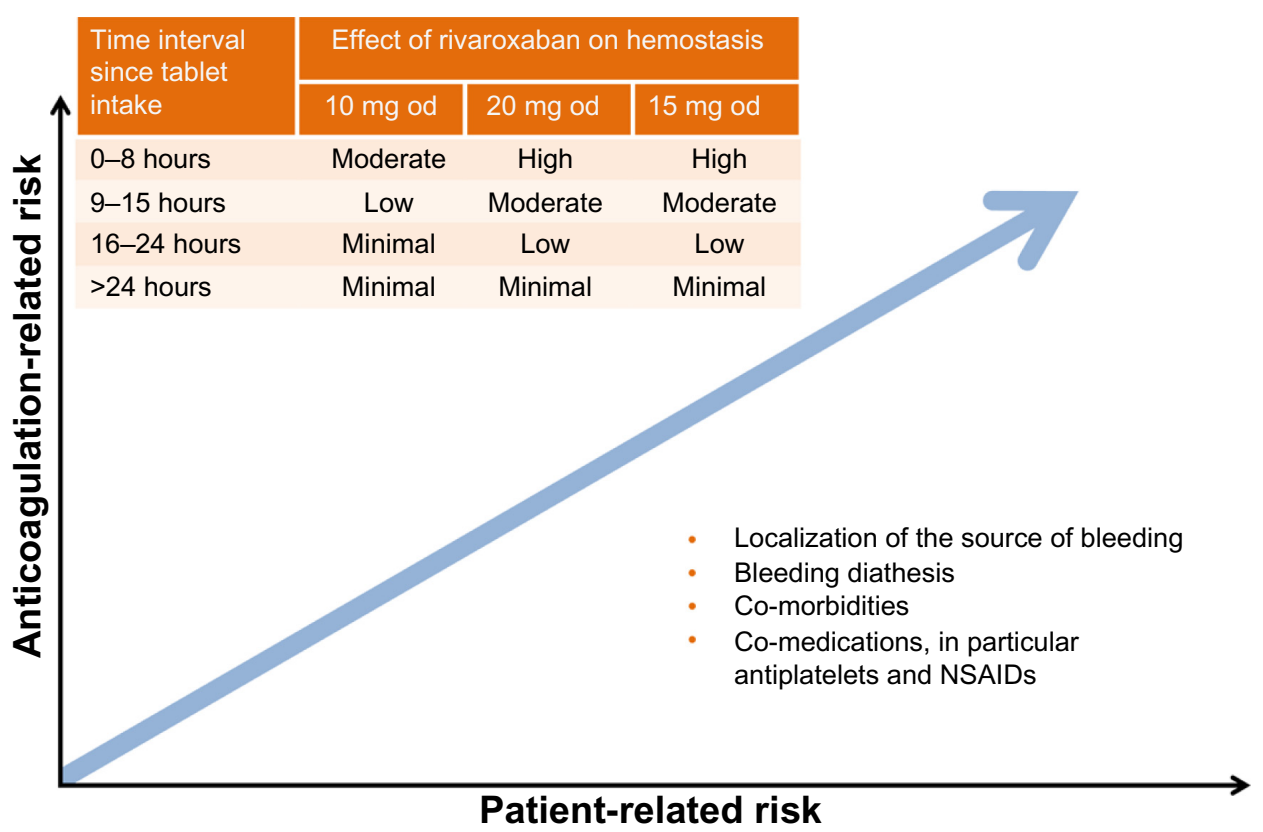

Figure 5 Assessment of bleeding risk in patients receiving rivaroxaban: anticoagulant-related and patient-related risk factors. Abbreviations: bid, twice daily; NSAID, nonsteroidal anti-inflammatory drug; od, once daily. 
Patients receiving rivaroxaban who

experience bleeding complications

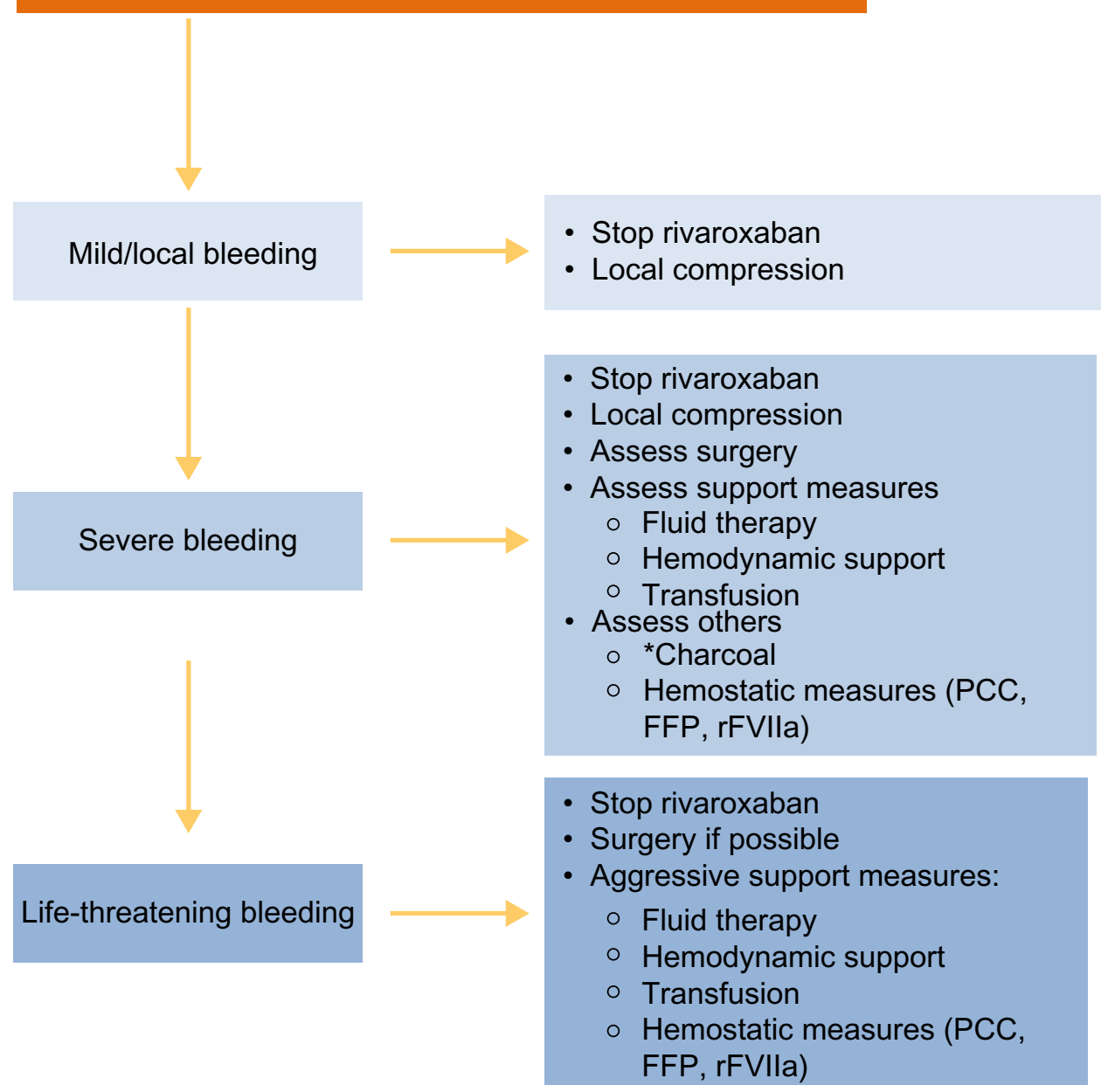

Figure 6 Recommended strategies for managing bleeding events.

Notes: Rivaroxaban is not dialyzable because of its high plasma protein binding. In patients with mild/local bleeding, the balance between the need to manage a bleeding event and the increased risk of stroke in nonanticoagulated patients should be considered. *Activated charcoal may only be useful to reduce rivaroxaban absorption after overdose if administered shortly after tablet intake.

Abbreviations: FFP, fresh frozen plasma; PCC, prothrombin complex concentrate; rFVlla, recombinant factor VIla.

- When bleeding has ceased, the risks of thrombotic and further bleeding events should be assessed and rivaroxaban restarted when appropriate

- Minor bleeding events can result in unwarranted interruptions of rivaroxaban therapy; therefore, we recommend that patients should be educated about the increased risk of stroke if anticoagulation is stopped or interrupted

- In patients who develop an extracerebral intracranial hemorrhage, such as subdural or subarachnoid bleeding, rivaroxaban should be temporarily discontinued; the duration of discontinuation will depend on the location and severity of the bleeding and on any procedure used (eg, craniotomy)
- In patients who experience a hemorrhagic stroke, rivaroxaban should be interrupted until the patient's condition stabilizes. Given the complexity of any clinical situation, it is not possible to provide definitive guidance on when rivaroxaban therapy should be resumed for secondary prevention after hemorrhagic stroke, and clinical practice should be based on the experience with VKAs in this setting. ${ }^{45-47}$

\section{Laboratory testing of rivaroxaban}

Rivaroxaban showed predictable pharmacokinetics and pharmacodynamics in the Phase I and Phase II studies. ${ }^{3}$ In addition, none of the eleven Phase III studies of rivaroxaban routinely measured coagulation, further confirming that 
routine coagulation monitoring is not required. However, in practice, coagulation measurement may be useful in certain clinical circumstances and patient populations, such as in suspected overdose, in patients with a hemorrhagic or thromboembolic event during treatment with an anticoagulant, in those with acute renal failure, or in patients who require urgent surgery. ${ }^{31,48}$ Although PT levels measured using a reagent sensitive to rivaroxaban (such as Neoplastin Plus $^{\circledR}$; Diagnostica Stago Inc, Asnières-sur-Seine, France) correlate with rivaroxaban plasma concentrations, the PT test is not suitable for quantitative measurement of rivaroxaban exposure. ${ }^{49}$ The PT test results vary markedly with different thromboplastins and cannot be corrected with the conventional INR system; ${ }^{49}$ therefore, the INR must not be used, for rivaroxaban, with any $\mathrm{PT}$ reagent. In contrast, anti-factor Xa chromogenic assays can be used to quantitatively measure a wide range of rivaroxaban plasma levels. ${ }^{50-52}$ Rivaroxaban calibrators are now commercially available for use with these assays (eg, from Technoclone GmbH, Vienna, Austria; Hyphen Biomed, Neuville-sur-Oise, France; and Diagnostica Stago Inc). ${ }^{33}$ However, there are currently no clinical data showing an association between the measured trough or peak drug levels and thrombotic or bleeding risk.

\section{Recommendations}

- Anti-factor Xa assays are recommended for quantitative measurements of rivaroxaban plasma levels

- PT (measured with a reagent sensitive to rivaroxaban) may be useful for confirming the absence or presence of an anticoagulant effect (if the blood sampling time is known), when anti-factor Xa assays are not available

- When interpreting the test results, blood sampling time in relation to dosing must be considered, ie, whether the values represent peak or trough concentrations.

\section{Conclusion}

Rivaroxaban od is an approved therapeutic option that has demonstrated a favorable benefit-risk profile compared with warfarin, in a Phase III study on the prevention of stroke or systemic embolism in patients with nonvalvular AF. Similar to other NOACs, rivaroxaban overcomes several practical issues associated with VKA therapy, potentially simplifying patient management. Careful patient selection, based on an assessment of the overall patient presentation, is critical to avoiding inappropriate use of rivaroxaban. To ensure patient compliance, treating physicians are strongly encouraged to inform their patients to carry a "patient card" describing essential information about their anticoagulant therapy, as well as to educate their patients about the importance of strict adherence to the prescribed regimen at each visit. ${ }^{31}$ As experience with rivaroxaban increases in routine clinical practice, it is likely that the practical guidance recommendations will continue to be refined, potentially further improving patient outcomes. It is hoped that the recommendations provided in this paper will guide the responsible use of rivaroxaban in patients with nonvalvular AF, to ensure the clinical benefit of rivaroxaban is maintained in routine clinical practice.

\section{Author contributions}

All the authors contributed equally to the development of this manuscript and are fully responsible for its contents.

\section{Acknowledgments}

The authors would like to acknowledge Yong-Ling Liu, who provided editorial support with funding from Bayer HealthCare Pharmaceuticals and Janssen Research and Development, LLC.

\section{Disclosure}

The recommendations provided in this paper are based on the clinical expertise of the authors. The authors received no financial support or other compensation related to the development of this paper. Bayer HealthCare reviewed the paper for the factual correctness of the rivaroxaban data but had no influence on the recommendations.

$\mathrm{S}$ Haas has received honoraria from Bayer HealthCare, Bristol-Myers Squibb, Boehringer Ingelheim, CSL Behring, Daiichi-Sankyo, and Sanofi-Aventis. C Bode has received honoraria from Bayer HealthCare. B Norrving has acted as consultant for Bayer HealthCare, Servier, Syngis, and Allergan, and has received royalties for a book published by the Karolinska University Press. AGG Turpie has acted as a consultant for Bayer HealthCare, Janssen Research and Development, LLC, Astellas, Portola, and Takeda, and is a member of the speakers' bureaus of GlaxoSmithKline and Pfizer.

The authors report no other conflicts of interest in this work.

\section{References}

1. Bayer Pharma AG. [Xarelto ${ }^{\circledR}$ ] Annex I. Summary of Product Characteristics. Leverkusen: Bayer Pharma AG; 2013. Available from: http://www.ema.europa.eu/docs/en_GB/document_library/EPAR_-Product_Information/human/000944/WC500057108.pdf. Accessed November 15, 2013. 
2. Janssen Pharmaceuticals Inc. [Xarelto $\left.{ }^{\circledR}\right]$ Highlights of Prescribing Information. Titusville, NJ: Janssen Pharmaceuticals Inc; 2013. Available from: http://www.accessdata.fda.gov/drugsatfda_docs/ label/2013/202439s0081bl.pdf. Accessed December 22, 2013.

3. Perzborn E, Roehrig S, Straub A, Kubitza D, Misselwitz F. The discovery and development of rivaroxaban, an oral, direct factor Xa inhibitor. Nat Rev Drug Discov. 2011;10(1):61-75.

4. Camm AJ, Lip GY, De Caterina R, et al; ESC Committee for Practice Guidelines (CPG). 2012 focused update of the ESC Guidelines for the management of atrial fibrillation: an update of the 2010 ESC Guidelines for the management of atrial fibrillation. Developed with the special contribution of the European Heart Rhythm Association. Eur Heart J. 2012;33(21):2719-2747.

5. Gage BF, Waterman AD, Shannon W, et al. Validation of clinical classification schemes for predicting stroke. Results from the National Registry of Atrial Fibrillation. JAMA. 2001;285(22):2864-2870.

6. Connolly SJ, Ezekowitz MD, Yusuf S, et al; RE-LY Steering Committee and Investigators. Dabigatran versus warfarin in patients with atrial fibrillation. N Engl J Med. 2009;361(12):1139-1151.

7. Granger CB, Alexander JH, McMurray JJ, et al; ARISTOTLE Committees and Investigators. Apixaban versus warfarin in patients with atrial fibrillation. $N$ Engl J Med. 2011;365(11):981-992.

8. Patel MR, Mahaffey KW, Garg J, et al; ROCKET AF Investigators. Rivaroxaban versus warfarin in nonvalvular atrial fibrillation. $N$ Engl J Med. 2011;365(10):883-891.

9. Fox KA, Piccini JP, Wojdyla D, et al. Prevention of stroke and systemic embolism with rivaroxaban compared with warfarin in patients with non-valvular atrial fibrillation and moderate renal impairment. Eur Heart J. 2011;32(19):2387-2394.

10. Hankey GJ, Patel MR, Stevens SR, et al; ROCKET AF Steering Committee Investigators. Rivaroxaban compared with warfarin in patients with atrial fibrillation and previous stroke or transient ischaemic attack: a subgroup analysis of ROCKET AF. Lancet Neurol. 2012;11(4):315-322.

11. Mahaffey KW, White HD, Nessel CC, et al. Ischemic cardiac outcomes in patients with $\mathrm{AF}$ treated with vitamin $\mathrm{K}$ antagonism or Factor Xa inhibition: results from the ROCKET AF trial. Circulation. 2011; 124(Suppl 21):A13482. Abstract.

12. Mueck W, Eriksson BI, Bauer KA, et al. Population pharmacokinetics and pharmacodynamics of rivaroxaban - an oral, direct factor Xa inhibitor - in patients undergoing major orthopaedic surgery. Clin Pharmacokinet. 2008;47(3):203-216.

13. Mueck W, Lensing AW, Agnelli G, Decousus H, Prandoni P, Misselwitz F. Rivaroxaban: population pharmacokinetic analyses in patients treated for acute deep-vein thrombosis and exposure simulations in patients with atrial fibrillation treated for stroke prevention. Clin Pharmacokinet 2011;50(10):675-686.

14. Graff J, von Hentig N, Misselwitz F, et al. Effects of the oral, direct factor xa inhibitor rivaroxaban on platelet-induced thrombin generation and prothrombinase activity. J Clin Pharmacol. 2007;47(11):1398-1407.

15. Kubitza D, Becka M, Voith B, Zuehlsdorf M, Wensing G. Safety, pharmacodynamics, and pharmacokinetics of single doses of BAY 59-7939, an oral, direct factor Xa inhibitor. Clin Pharmacol Ther. 2005;78(4):412-421.

16. Kubitza D, Becka M, Mueck W, et al. Effects of renal impairment on the pharmacokinetics, pharmacodynamics and safety of rivaroxaban, an oral, direct Factor Xa inhibitor. Br J Clin Pharmacol. 2010;70(5):703-712.

17. Helou R. Should we continue to use the Cockcroft-Gault formula? Nephron Clin Pract. 2010;116(3):c172-c185; discussion c186.

18. Camm AJ, Kirchhof P, Lip GY, et al; European Heart Rhythm Association; European Association for Cardio-Thoracic Surgery. Guidelines for the management of atrial fibrillation: the Task Force for the Management of Atrial Fibrillation of the European Society of Cardiology (ESC). Eur Heart J. 2010;31(19):2369-2429.

19. Levey AS, Coresh J, Balk E, et al; National Kidney Foundation. National Kidney Foundation practice guidelines for chronic kidney disease: evaluation, classification, and stratification. Ann Intern Med. 2003;139(2):137-147.
20. Kubitza D, Becka M, Roth A, Mueck W. Dose-escalation study of the pharmacokinetics and pharmacodynamics of rivaroxaban in healthy elderly subjects. Curr Med Res Opin. 2008;24(10): 2757-2765.

21. Kubitza D, Becka M, Wensing G, Voith B, Zuehlsdorf M. Safety, pharmacodynamics, and pharmacokinetics of BAY 59-7939 - an oral, direct Factor Xa inhibitor - after multiple dosing in healthy male subjects. Eur J Clin Pharmacol. 2005;61(12):873-880.

22. Kubitza D, Becka M, Roth A, Mueck W. The influence of age and gender on the pharmacokinetics and pharmacodynamics of rivaroxaban - an oral, direct Factor Xa inhibitor. J Clin Pharmacol. 2013;53(3):249-255.

23. Kubitza D, Becka M, Zuehlsdorf M, Mueck W. Body weight has limited influence on the safety, tolerability, pharmacokinetics, or pharmacodynamics of rivaroxaban (BAY 59-7939) in healthy subjects. J Clin Pharmacol. 2007;47(2):218-226.

24. Hori M, Matsumoto M, Tanahashi N, et al; J-ROCKET AF Study Investigators. Rivaroxaban vs warfarin in Japanese patients with atrial fibrillation - the J-ROCKET AF study. Circ J. 2012;76(9): 2104-2111.

25. Mueck W, Stampfuss J, Kubitza D, Becka M. Clinical pharmacokinetic and pharmacodynamic profile of rivaroxaban. Clin Pharmacokinet. DOI:10.1007/s40262-013-0100-7.

26. Pugh RN, Murray-Lyon IM, Dawson JL, et al. Transection of the oesophagus for bleeding oesophageal varices. Br J Surg. 1973;60(8):646-649.

27. Kubitza D, Roth A, Becka M, et al. Effect of hepatic impairment on the pharmacokinetics and pharmacodynamics of a single dose of rivaroxaban, an oral, direct Factor Xa inhibitor. Br J Clin Pharmacol. 2013;76(1):89-98.

28. Goodman SG, Wojdyla DM, White HD, et al. Predictors of major bleeding risk: insights from the rivaroxaban once-daily oral direct factor $\mathrm{Xa}$ inhibition compared with vitamin $\mathrm{K}$ antagonism for prevention of stroke and embolism trial in atrial fibrillation (ROCKET AF). Circulation. 2011;124(Suppl 21):A16903. Abstract.

29. Mueck W, Kubitza D, Becka M. Co-administration of rivaroxaban with drugs that share its elimination pathways: pharmacokinetic effects in healthy subjects. Br J Clin Pharmacol. 2013;76(3):455-466.

30. Abraham NS, Hlatky MA, Antman EM, et al; ACCF/ACG/AHA. ACCF/ ACG/AHA 2010 Expert Consensus Document on the concomitant use of proton pump inhibitors and thienopyridines: a focused update of the ACCF/ACG/AHA 2008 expert consensus document on reducing the gastrointestinal risks of antiplatelet therapy and NSAID use: a report of the American College of Cardiology Foundation Task Force on Expert Consensus Documents. Circulation. 2010;122(24): 2619-2633.

31. Heidbuchel H, Verhamme P, Alings M, et al; European Heart Rhythm Association. European Heart Rhythm Association Practical Guide on the use of new oral anticoagulants in patients with non-valvular atrial fibrillation. Europace. 2013;15(5):625-651.

32. Keller C, Matzdorff AC, Kemkes-Matthes B. Pharmacology of warfarin and clinical implications. Semin Thromb Hemost. 1999;25(1): 13-16.

33. Turpie AG, Kreutz R, Llau J, Norrving B, Haas S. Management consensus guidance for the use of rivaroxaban - an oral, direct factor Xa inhibitor. Thromb Haemost. 2012;108(5):876-886.

34. Lansberg MG, O’Donnell MJ, Khatri P, et al; American College of Chest Physicians. Antithrombotic and Thrombolytic Therapy for Ischemic Stroke: Antithrombotic Therapy and Prevention of Thrombosis. 9th ed: American College of Chest Physicians Evidence-Based Clinical Practice Guidelines. Chest. 2012;141(Suppl 2):e601S-e636S.

35. The European Stroke Organisation (ESO) Executive Committee; ESO Writing Committee. Guidelines for management of ischaemic stroke and transient ischaemic attack 2008. Cerebrovasc Dis. 2008;25(5): 457-507.

36. European Stroke Organisation. Consensus statement 2012: Update on Intravenous Thrombolysis. Karolinska: European Stroke Organisation; 2012. Available from: http://www.strokeupdate.org/Cons_Reperf_ IVT_2012.aspx. Accessed December 20, 2013. 
37. Adams HP, del Zoppo G, Alberts MJ, et al; American Heart Association/ American Stroke Association Stroke Council; American Heart Association/American Stroke Association Clinical Cardiology Council; American Heart Association/American Stroke Association Cardiovascular Radiology and Intervention Council; Atherosclerotic Peripheral Vascular Disease Working Group; Quality of Care Outcomes in Research Interdisciplinary Working Group. Guidelines for the early management of adults with ischemic stroke: a guideline from the American Heart Association/American Stroke Association Stroke Council, Clinical Cardiology Council, Cardiovascular Radiology and Intervention Council, and the Atherosclerotic Peripheral Vascular Disease and Quality of Care Outcomes in Research Interdisciplinary Working Groups: The American Academy of Neurology affirms the value of this guideline as an educational tool for neurologists. Circulation. 2007;115(20):e478-e534.

38. Paciaroni M, Agnelli G, Corea F, et al. Early hemorrhagic transformation of brain infarction: rate, predictive factors, and influence on clinical outcome: results of a prospective multicenter study. Stroke. 2008;39(8): 2249-2256.

39. Lip GY, Huber K, Andreotti F, et al; European Society of Cardiology Working Group on Thrombosis. Management of antithrombotic therapy in atrial fibrillation patients presenting with acute coronary syndrome and/or undergoing percutaneous coronary intervention/stenting. Thromb Haemost. 2010;103(1):13-28.

40. Hamm CW, Bassand JP, Agewall S, et al; ESC Committee for Practice Guidelines. ESC Guidelines for the management of acute coronary syndromes in patients presenting without persistent ST-segment elevation: The Task Force for the management of acute coronary syndromes (ACS) in patients presenting without persistent ST-segment elevation of the European Society of Cardiology (ESC). Eur Heart J. 2011;32(23):2999-3054.

41. Vandvik PO, Lincoff AM, Gore JM, et al; American College of Chest Physicians. Primary and Secondary Prevention of Cardiovascular Disease: Antithrombotic Therapy and Prevention of Thrombosis. 9th ed: American College of Chest Physicians Evidence-Based Clinical Practice Guidelines. Chest. 2012;141(Suppl 2):e637S-e668S.

42. Mega JL, Braunwald E, Wiviott SD, et al; ATLAS ACS 2-TIMI 51 Investigators. Rivaroxaban in patients with a recent acute coronary syndrome. N Engl J Med. 2012;366(1):9-19.

43. Eerenberg ES, Kamphuisen PW, Sijpkens MK, Meijers JC, Buller HR, Levi M. Reversal of rivaroxaban and dabigatran by prothrombin complex concentrate: a randomized, placebo-controlled, crossover study in healthy subjects. Circulation. 2011;124(14):1573-1579.
44. Marlu R, Hodaj E, Paris A, et al. Effect of non-specific reversal agents on anticoagulant activity of dabigatran and rivaroxaban: a randomised crossover ex vivo study in healthy volunteers. Thromb Haemost. 2012;108(2):217-224.

45. Schulman S. Resumption of oral anticoagulation after warfarinassociated intracerebral hemorrhage: no. Stroke. 2011;42(12): 3663-3664.

46. Steiner T. Resumption of oral anticoagulation after warfarin-associated intracerebral hemorrhage: yes. Stroke. 2011;42(12):3661-3662.

47. Majeed A, Kim YK, Roberts RS, Holmström M, Schulman S. Optimal timing of resumption of warfarin after intracranial hemorrhage. Stroke. 2010;41(12):2860-2866.

48. Lindhoff-Last E, Ansell J, Spiro T, Samama MM. Laboratory testing of rivaroxaban in routine clinical practice: when, how, and which assays. Ann Med. 2013;45(5-6):423-429.

49. Lindhoff-Last E, Samama MM, Ortel TL, Weitz JI, Spiro TE. Assays for measuring rivaroxaban: their suitability and limitations. Ther Drug Monit. 2010;32(6):673-679.

50. Samama MM, Amiral J, Guinet C, Perzborn E, Depasse F. An optimised, rapid chromogenic assay, specific for measuring direct factor Xa inhibitors (rivaroxaban) in plasma. Thromb Haemost. 2010;104(5): 1078-1079.

51. Samama MM, Contant G, Spiro TE, et al; Rivaroxaban Anti-Factor Xa Chromogenic Assay Field Trial Laboratories. Evaluation of the antifactor Xa chromogenic assay for the measurement of rivaroxaban plasma concentrations using calibrators and controls. Thromb Haemost. 2012;107(2):379-387.

52. Asmis LM, Alberio L, Angelillo-Scherrer A, et al. Rivaroxaban: Quantification by anti-FXa assay and influence on coagulation tests: a study in 9 Swiss laboratories. Thromb Res. 2012;129(4):492-498.

53. Boehringer Ingelheim International GmbH. [Pradaxa ${ }^{\circledR}$ Annex I. Summary of Product Characteristics. Ingelheim am Rhein: Boehringer Ingelheim International $\mathrm{GmbH} ; 2013$. Available from: http:// www.ema.europa.eu/docs/en_GB/document_library/EPAR_-_ Product_Information/human/000829/WC500041059.pdf. Accessed December 22, 2013

54. Bristol-Myers Squibb/Pfizer EEIG. [Eliquis ${ }^{\circledR}$ ] Annex I. Summary of Product Characteristics. Uxbridge: Bristol-Myers Squibb; 2013. Available from: http://www.ema.europa.eu/docs/en_GB/document_ library/EPAR_-_Product_Information/human/002148/WC500107728. pdf. Accessed December 22, 2013.

55. Pisters R, Lane DA, Nieuwlaat R, et al. A novel user-friendly score (HASBLED) to assess 1-year risk of major bleeding in patients with atrial fibrillation: the Euro Heart Survey. Chest. 2010;138(5):1093-1100.
Vascular Health and Risk Management

\section{Publish your work in this journal}

Vascular Health and Risk Management is an international, peerreviewed journal of therapeutics and risk management, focusing on concise rapid reporting of clinical studies on the processes involved in the maintenance of vascular health; the monitoring, prevention and treatment of vascular disease and its sequelae; and the involvement of

\section{Dovepress}

metabolic disorders, particularly diabetes. This journal is indexed on PubMed Central and MedLine. The manuscript management system is completely online and includes a very quick and fair peer-review system, which is all easy to use. Visit http://www.dovepress.com/ testimonials.php to read real quotes from published authors. 